\title{
Demographics of toxic exposures presenting to three public hospital emergency departments in Singapore 2001-2003
}

\author{
R. Ponampalam • Hock Heng Tan $\cdot$ Kee Chong Ng • \\ Wee Yee Lee $\cdot$ Sau Chew Tan
}

Received: 10 July 2008 / Accepted: 27 December 2008 / Published online: 4 February 2009

(C) Springer-Verlag London Ltd 2009

\begin{abstract}
Background The demographics of poisoned patients and the circumstances of toxic exposure have not been evaluated in Singapore for the last 10 years.

Aim This study aims to give an estimate of the burden of poisoning in Singapore from the emergency department's (ED) perspective.

Method A retrospective study of toxic exposure was conducted over a period of 3 years from 2001 to 2003 at the ED of three public hospitals, one being a paediatric hospital.

Results There were 9,212 cases of toxic exposures during the study period, which constituted $0.94 \%$ of total ED attendances. The poison exposure rate was 1.7 per 1,000 population and the estimated case fatality rate was 0.8 per $1,000 \mathrm{ED}$ attendances for poisoning. The mean age of patients was 29 years and the majority were male (63.3\%). Non-accidental injuries constituted $60 \%$ of the cohort. Alcohol was the commonest toxin involved (26\%), but
\end{abstract}

The views expressed in this paper are those of the author(s) and not those of the editors, editorial board or publisher.

R. Ponampalam $(\bowtie) \cdot$ S. C. Tan

Department of Emergency Medicine, Singapore General Hospital,

Outram Road,

Singapore 169608, Singapore

e-mail: gaerpo@sgh.com.sg

H. H. Tan - W. Y. Lee

Department of Emergency Medicine, Changi General Hospital,

2 Simei Street 3,

Singapore 629889, Singapore

K. C. $\mathrm{Ng}$

Paediatric Emergency Department, Kandang Kerbau Hospital,

100 Bukit Timah Road,

Singapore 229889, Singapore paracetamol (acetaminophen) was the most common pharmaceutical agent (33\%). The mean time of exposure to ED presentation was $3.3 \mathrm{~h}$. About one third of the patients were admitted of whom 157 patients (4.7\% of admitted cases) required intensive care management.

Conclusion The patients were predominantly young adults. This may suggest a need for poison prevention and chemical safety education to reduce the impact on this high-risk group. Although poisoning accounts for only $1 \%$ of the total ED attendance, a sizable proportion of them required inpatient care $(36.1 \%)$ with a significant proportion requiring intensive care management. However, it was also noted that a third of those who were admitted stayed for less than $24 \mathrm{~h}$, and hence a short-stay ward in the ED might be a cost-effective strategy to consider.

Keywords Poisoning · Singapore · Toxic exposures · Demographics

\section{Introduction}

In the USA, American Association of Poison Control Centers Toxic Exposure Surveillance System [1] data have shown the number of toxic exposures reported to the poison centres over the years to be high, exceeding over 2 million exposures and averaging 8.3 exposures per 1,000 population. Many other countries seem to have significant toxic exposure-related problems that are mostly unique to their socio-economic and cultural environment [2-9].

In Singapore, deaths from injuries, including poisoning, ranked as the fifth leading cause of death and the leading cause of hospitalization for the last 3 years from 2004 to 2006 according to national statistics [10]. Suicidal deaths by poisoning accounted for $5.5 \%$ of all suicide death cases 
from 1991 to 2000 [11]. The case fatality rate for patients admitted in a local intensive care unit (ICU) was $8 \%$ [12], although there was no fatality amongst paediatric cases admitted to the same hospital in another study [13]. A study conducted amongst medical practitioners in Singapore in 1998 [14], to which 1,071 physicians responded, gave their annual total workload of 55,832 toxicology and adverse drug reaction-related problems. It is clear that poisoning and toxic exposure are also prevalent in our society.

The demographics of poisoned patients and the circumstances of toxic exposure have not been evaluated in Singapore for the last 10 years $[12,13,15]$. The objective of this study was to achieve a baseline profile of patients with toxic exposure in Singapore and to have a better understanding of the causes of toxic exposure.

Singapore is a cosmopolitan city state island with a land area of $700 \mathrm{~km}^{2}$ and a population of approximately 4.2 million in 2004. There are six public general hospitals (including a children's hospital), which provide the bulk of the emergency care through their emergency departments (ED). The public sector admits about three quarters of all the patients in the country in terms of bed use [16]. This study captures the profile of patients with toxic exposures presenting to three of these public hospital ED. The workload of the three ED in this study represents slightly more than half $(57 \%)$ of the six public hospitals' ED attendance.

\section{Method}

A retrospective study of toxic exposure was conducted over a period of 3 years from 2001 to 2003 at the participating ED of three hospitals: Singapore General Hospital (SGH), Changi General Hospital (CGH) and Kandang Kerbau Hospital (KKH), the latter being the only children's public hospital in Singapore. Ethics Committee approval was obtained for the study from the SGH Institutional Review Board and agreed to by the Review Boards of the respective hospitals involved prior to the commencement of the study.

A standardized survey form was used to collect poisoning information. Patients were identified when they presented to the respective ED as well as through a search of the ICD code for poisoning as well as bite and sting cases. The information captured included: age, gender and race of patients, reasons for toxic exposure, toxin and its classification, quantity, routes of toxic exposure and ED management of these patients (use of decontamination procedures, antidotes and supportive care). The completed survey forms were collected and information on admission and discharges and outcomes were extracted from the inpatient medical records. All data from completed forms were entered into a database, Statistical Package (SPSS) version 10. Descriptive statistics were analysed and presented as means and percentages where appropriate.

\section{Results}

Cases included

There were 12,171 cases collected for the 3 years (20012003); 2,959 cases were excluded in our analysis because they were due to adverse effects of therapeutic treatment (463), allergic reactions to drugs $(1,771)$ and food (586) and also electrical injuries (54), needlestick injuries (77) or of unknown cause (8).

The remaining 9,212 cases were included in our study and constituted $0.94 \%$ of the total ED attendances for the three hospitals during that period ( 976,285 patients). The case load for the years 2001-2003 were 2,986, 2,833 and 3,393 cases, respectively.

\section{Poisoning data by causation}

The cases were stratified according to causation as illustrated in Table 1. The two major categories were accidental (A) versus non-accidental (NA).

In the accidental category, the exposures were deemed to be unintentional and there were three sub-categories. Industrial causes included poisoning exposure that were work related and were classified as industrial accidents. The sub-category of bites included any bite and sting inflicted by venomous creatures as well as non-venomous creatures, such as large mammals (dogs, cats, etc.) and insects and whose exposures were assumed to be accidental. All other exposures that occurred in non-work-related scenarios were classified as others. These included accidental exposure at home, during transport and fire incidents. Exposure that occurred at the workplace but not as a result of working

Table 1 Causes of toxic exposures

\begin{tabular}{lc}
\hline Causation & Number (\% of total) \\
\hline Accidental & $747(8.1)$ \\
Industrial & $1,480(16.1)$ \\
Bites and stings & $1,422(15.4)$ \\
Others & $3,649(39.6)$ \\
Total & \\
Non-accidental & $1,928(20.9)$ \\
DSH & $3,635(39.5)$ \\
Abuse and misuse, etc & $5,563(60.4)$ \\
Total &
\end{tabular}

DSH deliberate self-harm 
were classified under the others category. This category also included food poisoning as well as therapeutic errors resulting in overdose.

The non-accidental or intentional category has two subcategories. The deliberate self-harm (DSH) category included any exposure of harming oneself either from suicidal intent or from an acute stress reaction. The other category included all other intentional misuse and abuse of drugs or poisons that were not according to prescribed use and were used for reasons like recreational use for psychotropic effects, for malicious criminal intent as well as purposes of sabotage or terrorism. It also included drug withdrawal cases and human bites.

Non-accidental injuries constituted $60 \%$ of the cohort. A fifth of all the causes were due to deliberate self-harm. Industrial accident injuries made up $8 \%$ of the cohort.

\section{General epidemiology of toxic exposures}

The distribution of the cases by age and gender are shown in Tables 2 and 3 and the distribution of cases by race in Table 4. The mean age for poisoning exposure was 31.8 years (standard deviation of 16) and the median was 29 years with a range from 0.1 to 101 years. Paediatric cases (less than 13 years of age) constituted $7.4 \%$ of the cohort and the majority in this age group resulted from accidental exposure (91\%). Almost 50\% of the patients belonged to the age group 20-39 years of age and most were due to a non-accidental exposure $(61.9 \%)$.

Most toxic exposures occurred in males $(63.3 \%)$ and the male predominance is also seen for the different age groups (Table 3). However, proportionally more females were involved in non-accidental toxic exposures compared to their male counterparts. This is more pronounced in a sub-group analysis, which showed that in the DSH category $71 \%(1,368 / 1,928)$ of the patients were female.

Except for the Chinese, the Malays, Indians and other races had proportionally more toxic exposures compared to the national demographic distribution in the country. This is evident whether the cause is accidental or non-accidental but is more pronounced in the latter group.

Table 2 Distribution of toxic exposures by cause, age and gender

\begin{tabular}{lllllllll}
\hline Age/gender & $<6$ & $6-12$ & $13-19$ & $20-39$ & $40-59$ & $>60$ & Male & Female \\
\hline Accidental & 477 & 139 & 302 & 1,743 & 728 & 256 & 2,398 & 1,251 \\
Non- & 17 & 44 & 914 & 2,836 & 1,459 & 292 & 3,433 & 2,130 \\
$\quad$ accidental & & & & & & & & \\
$\begin{array}{l}\text { Total } \\
\%\end{array}$ & 494 & 183 & 1,216 & 4,579 & 2,187 & 548 & 5,831 & 3,381 \\
& 5.4 & 2.0 & 13.2 & 49.7 & 23.7 & 5.9 & 63.3 & 36.7 \\
\hline
\end{tabular}

Table 3 Distribution of toxic exposures by age and gender

\begin{tabular}{lllllll}
\hline Age/gender & $<6$ & $6-12$ & $13-19$ & $20-39$ & $40-59$ & $>60$ \\
\hline Male & 297 & 107 & 669 & 2,857 & 1,550 & 349 \\
Female & 197 & 76 & 547 & 1,722 & 637 & 199 \\
Total & 494 & 183 & 1,216 & 4,579 & 2,187 & 548 \\
\hline
\end{tabular}

Missing data for age 5

Poisoning agents and exposure

The list of agents exposed to are listed in Table 5. Alcohol was the most common poison involved $(27.8 \%)$ and pharmaceutical agents constituted 32.5\% (3,275/10,063). Paracetamol or acetaminophen (including combination formulations with paracetamol) was involved in $33 \%$ $(1085 / 3275)$ of all pharmaceuticals agents. The majority of bites and stings were from insects (800 cases), though there was a small proportion of marine envenomation $(97$ cases) and snakebites (38 cases).

Table 6 illustrates the number of agents involved per toxic exposure, the route of exposure, the place of exposure and the time delay from exposure to presentation at the hospital stratified by accidental versus non-accidental causes. The majority of the exposures involved only one agent or poison with the maximum number of agents exposed to being six (one case). However, if two or more agents were involved the cause for exposure would more likely be non-accidental $(911 / 5,464$ or $16.7 \%)$ compared to accidental $(71 / 3,598$ or $2 \%)$. The majority of accidental exposures occurred via the non-oral route $(82.6 \%)$ while the reverse was true of non-accidental cases $(88.6 \%$ via the oral route). Non-accidental bites were all human bites.

The commonest place of exposure was in the home (39.2\%). However, a large majority of toxic exposures occurred at an unspecified location. Not all the cases that occurred at the workplace were classified as industrial accidents as they may not be work related like insect bites. Only about $16.3 \%$ of the cases presented to the ED within $2 \mathrm{~h}$ of exposure. The mean time from exposure to ED presentation for accidental cases was $2.4 \mathrm{~h}$ and for non-accidental

Table 4 Distribution of toxic exposures by race

\begin{tabular}{lcclc}
\hline Cause & Chinese & Malay & Indians & Others \\
\hline $\begin{array}{l}\text { National racial } \\
\quad \text { distribution }\end{array}$ & $76.0 \%$ & $13.8 \%$ & $8.4 \%$ & $1.8 \%$ \\
Accidental & 2,262 & 502 & 419 & 466 \\
& $(62 \%)$ & $(13.7 \%)$ & $(11.5 \%)$ & $(12.8 \%)$ \\
Non-accidental & 3,071 & 946 & 1,028 & 518 \\
& $(55.2 \%)$ & $(17.1 \%)$ & $(18.5 \%)$ & $(9.3 \%)$ \\
Total & 5,333 & 1,448 & 1,447 & 984 \\
$\%$ & 57.8 & 15.7 & 15.7 & 10.7 \\
\hline
\end{tabular}


Table 5 Agents involved in toxic exposures

\begin{tabular}{|c|c|}
\hline Toxin & $\begin{array}{l}\text { Frequency } \\
\text { (\% of total exposures) }\end{array}$ \\
\hline Alcohol & $2,802(27.8)$ \\
\hline $\begin{array}{l}\text { Analgesics } \\
\text { (paracetamol, NSAIDs, opiates) }\end{array}$ & $1,330(13.2)$ \\
\hline $\begin{array}{l}\text { Sedatives } \\
\text { (benzodiazepines, barbiturates) }\end{array}$ & $849(8.4)$ \\
\hline Antidepressants & $215(2.1)$ \\
\hline Antipsychotics & $76(0.8)$ \\
\hline Anticonvulsants & $41(0.4)$ \\
\hline Cough \& cold preparations & $325(3.2)$ \\
\hline Antimicrobials & $77(0.8)$ \\
\hline $\begin{array}{l}\text { Anticoagulants } \\
\text { (heparin, warfarin) }\end{array}$ & $5(0.1)$ \\
\hline $\begin{array}{l}\text { Asthma medications } \\
\text { (salbutamol, Atrovent, theophylline, } \\
\text { steroids) }\end{array}$ & $104(1.0)$ \\
\hline $\begin{array}{l}\text { Endocrine medications } \\
\text { (oral hypoglycaemics \& insulin) }\end{array}$ & $57(0.6)$ \\
\hline $\begin{array}{l}\text { Gastrointestinal medications } \\
\text { (laxatives, antispasmodics, antacids) }\end{array}$ & $121(1.2)$ \\
\hline $\begin{array}{l}\text { Cardiac medications } \\
\text { (antihypertensives, antiarrhythmics, digoxin) }\end{array}$ & $75(0.7)$ \\
\hline Vitamins \& nutritional supplements & $45(0.4)$ \\
\hline Illicit drugs & $150(1.5)$ \\
\hline Food poisoning & $91(0.9)$ \\
\hline Bites \& stings & $1,480(14.7)$ \\
\hline Pesticides & $69(0.7)$ \\
\hline Cleaning products-domestic & $314(3.1)$ \\
\hline Cleaning products - medical & $87(0.9)$ \\
\hline Industrial chemicals & $1,046(10.4)$ \\
\hline $\begin{array}{l}\text { Personal care products } \\
\text { (cosmetics, perfumes) }\end{array}$ & $71(0.7)$ \\
\hline Smoke inhalation & $139(1.4)$ \\
\hline Traditional medications & $66(0.7)$ \\
\hline Others/unknown & $428(4.3)$ \\
\hline Total & 10,063 \\
\hline
\end{tabular}

NSAIDs non-steroidal anti-inflammatory drugs

cases was $4.2 \mathrm{~h}$ with an average mean time of $3.3 \mathrm{~h}$ for all cases. However, the time from exposure to presentation was unknown for a large majority of cases (52.1\%).

\section{Poisoning management}

The lists of procedures performed and antidotes used in the ED are listed in Table 7. A total of 153 patients required advanced airway management. The most common decontamination procedures were use of activated charcoal and gastric lavage. The most common antidotes used were $\mathrm{N}$-acetyl-L-cysteine (NAC) (6.2\%) followed by flumazenil and naloxone. Of note is that none of the patients underwent haemodialysis or other invasive enhanced elimination techniques.
Disposition and outcome of patients

The disposal and outcome of patients are detailed in Table 8. About one third of the patients were admitted and a third of them were discharged without any follow-up. Amongst those who were admitted, non-accidental cases comprised $76.7 \%(2,553 / 3,328)$ of the cases. The remaining one third of the patients were either referred to other hospitals or discharged with follow-up at the outpatient specialist clinics or the general polyclinic. A total of 72 patients were referred directly to the main psychiatric hospital. There were 113 referrals to the medical social worker and 189 referrals to the psychiatrist.

A total of 157 patients (4.7\% of admitted cases) required intensive care monitoring either in the ICU or high dependency wards with a mean length of stay in the monitored facility of 2.1 days. The majority $(73.7 \%)$ of patients admitted had a length of stay in hospital greater than $24 \mathrm{~h}$. Non-accidental toxic exposures $(80 \%)$ were more likely to stay longer in hospitals compared to accidental exposures (53\%). The average length of stay was 3 days with the longest stay reaching 8 days.

There were seven fatalities $(0.08 \%)$ in this cohort. Of these, three patients were workers involved in an industrial

Table 6 Characteristics of toxic exposure

\begin{tabular}{|c|c|c|c|}
\hline & Accidental & Non-accidental & Total \\
\hline \multicolumn{4}{|l|}{ Number of agents } \\
\hline 1 & 3,527 & 4,553 & $8,080(88.5 \%)$ \\
\hline 2 & 46 & 628 & $674(7.3 \%)$ \\
\hline$>2$ & 25 & 283 & $308(3.3 \%)$ \\
\hline \multicolumn{4}{|l|}{ Missing data: 150} \\
\hline \multicolumn{4}{|l|}{ Route of exposure } \\
\hline Oral & 635 & 4,927 & 5,562 \\
\hline Cutaneous & 1,028 & 59 & 1,087 \\
\hline Inhalation & 174 & 546 & 720 \\
\hline Ocular & 370 & 7 & 377 \\
\hline Parenteral & 4 & 5 & 9 \\
\hline Bites and stings & 1,428 & 15 & 1,443 \\
\hline Unknown & 9 & 5 & 14 \\
\hline \multicolumn{4}{|l|}{ Place of exposure } \\
\hline Home & 1,385 & 2,222 & $3,607(39.2 \%)$ \\
\hline Work & 832 & 45 & $877(9.5 \%)$ \\
\hline $\begin{array}{l}\text { Recreational places, } \\
\text { e.g. pubs, etc. }\end{array}$ & 120 & 217 & $337(3.7 \%)$ \\
\hline Non-specified & 1,309 & 3,069 & $4,378(47.6 \%)$ \\
\hline \multicolumn{4}{|l|}{ Missing data: 13} \\
\hline \multicolumn{4}{|c|}{ Time delay to presentation at the ED } \\
\hline$<1 \mathrm{~h}$ & 416 & 262 & $678(7.4 \%)$ \\
\hline $1-2 \mathrm{~h}$ & 447 & 378 & $825(8.9 \%)$ \\
\hline $2-6 \mathrm{~h}$ & 474 & 853 & $1,327(14.4 \%)$ \\
\hline $6-24 \mathrm{~h}$ & 351 & 861 & $1,212(13.1 \%)$ \\
\hline$>24 \mathrm{~h}$ & 285 & 81 & $366(4.0 \%)$ \\
\hline Unknown & 1,676 & 3,128 & $4,804(52.1 \%)$ \\
\hline
\end{tabular}


Table 7 Summary of poison management interventions

\begin{tabular}{|c|c|}
\hline & Number \\
\hline \multicolumn{2}{|l|}{ Critical interventions } \\
\hline Advanced airway management (intubations) & 153 \\
\hline \multicolumn{2}{|l|}{ Decontamination and elimination interventions } \\
\hline Activated charcoal, single dose & $1,021(11 \%)$ \\
\hline Gastric lavage & $337(3.7 \%)$ \\
\hline Whole bowel irrigation & 1 \\
\hline Ocular decontamination & 262 \\
\hline Skin decontamination (decontamination shower) & 40 \\
\hline Ipecac & 2 \\
\hline Multidose activated charcoal & 18 \\
\hline Forced alkaline diuresis & 3 \\
\hline Others (forced saline diuresis) & 167 \\
\hline \multicolumn{2}{|l|}{ Antidotes } \\
\hline$N$-acetyl-L-cysteine & 584 \\
\hline Flumazenil & 69 \\
\hline Naloxone & 39 \\
\hline Intravenous dextrose $(50 \%)$ & 31 \\
\hline Sodium bicarbonate & 12 \\
\hline Atropine & 10 \\
\hline Benztropine & 10 \\
\hline Pralidoxime & 6 \\
\hline Calcium gluconate gel paste and IV calcium & 5 \\
\hline Methionine & 4 \\
\hline Digoxin Fab & 1 \\
\hline Glucagon & 1 \\
\hline Pyridoxine & 1 \\
\hline
\end{tabular}

explosion and sustained significant chemical and thermal burns with inhalational injuries. The remaining three patients died from deliberate self-harm attempts and the agents involved tricyclic antidepressants in the first case, corrosives in the second case and in the third case a combination of Anarex (paracetamol and orphenadrine), Vioxx (rofecoxib) and Clorox (sodium hypochlorite). The last patient was the only paediatric death involving a 6-year-old child who accidentally consumed a few mouthfuls of industrial strength detergent (brought home and stored in an unlabelled bottle).

\section{Discussion}

The burden of poisoning in Singapore has not been studied in the past. This study gives the demographics of toxic exposures from the perspective of the ED managing acute conditions. A crude extrapolation of these data to estimate the catchment population of this study could be attempted. The Singapore population in 2004 was 4.2 million. The medical services of this country are divided into the public and private sectors with the public sector handling $76 \%$ of all admissions to hospitals in 2004 [16]. The case load seen at the three general hospital ED accounted for slightly more than half (57\%) of the attendances at all public hospital ED. The estimated catchment population would thus be 1.8 million. Hence, the estimated attendance rate for poisoning cases per year would be 1.7 per 1,000 population (taking an average of about 3,000 toxic exposure cases per year). This is comparable to the poison load in most developed countries (2.7-8.3) [1, 8]. The ED attendance rate for poisoning $(0.94 \%)$ is also comparable to that in other centres $(0.18-2.6 \%)$ [5-8].

There is a noted wide variation in case fatality rates from amongst the different centres in the world with Iran at 5.7 [4], China at 24 [7] and Turkey at 28 [5] per 1,000 ED attendances, respectively. In the USA, the case fatality is noted to be approximately 0.5 per 1,000 poisoning exposure cases [1]. The case fatality rate in our study is approximately 0.8 per 1,000 ED attendances although poisoning constituted $5.5 \%$ of all suicide death cases [11]. This could suggest that survival for patients who made it to the hospital is generally good. However, comparison is not possible with case fatality ratios from previous local epidemiological data because the denominators were different $[12,13]$.

The patients who are mainly affected are young adults at the prime of their career. The morbidity sustained by them would affect their productivity and result in economic losses. However, the majority of cases were non-accidental, which would be difficult to prevent with simple safety measures and education. However, implementing procedures to improve workplace safety could help reduce industrial accidents involving chemical exposure. Young

Table 8 Disposition and outcomes of toxic exposures

\begin{tabular}{|c|c|c|c|}
\hline & Accidental & Non-accidental & Total \\
\hline \multicolumn{4}{|l|}{ Disposition } \\
\hline Admitted & 775 & 2,553 & $3,328(36.1 \%)$ \\
\hline Died & 4 & 3 & 7 \\
\hline \multicolumn{4}{|l|}{ Discharged } \\
\hline With follow-up & 1,461 & 339 & 1,800 \\
\hline No follow-up & 1,285 & 2,347 & $3,632(39.3 \%)$ \\
\hline $\begin{array}{l}\text { Discharged against } \\
\text { doctors advice }\end{array}$ & 52 & 209 & 261 \\
\hline $\begin{array}{l}\text { Referred to other } \\
\text { hospitals (including } \\
\text { psychiatric hospital) }\end{array}$ & 58 & 98 & 156 \\
\hline Total & 3,635 & 5,549 & 9,184 \\
\hline \multicolumn{4}{|l|}{ Missing data: 28} \\
\hline \multicolumn{4}{|l|}{$\begin{array}{l}\text { Outcome for admitted } \\
\text { patients }\end{array}$} \\
\hline \multicolumn{4}{|l|}{ Type of ward } \\
\hline General ward & 724 & 2,447 & 3,171 \\
\hline High dependancy/ICU & 51 & 106 & $157(4.7 \%)$ \\
\hline \multicolumn{4}{|l|}{ Length of stay (LOC) } \\
\hline LOS $<24 \mathrm{~h}$ & 364 & 511 & 875 \\
\hline LOS $>24 \mathrm{~h}$ & 411 & 2,042 & $2,453(73.7 \%)$ \\
\hline
\end{tabular}


children tend to be exposed to poisoning accidentally and most of the cases occurred at home. Hence, education on poison prevention could be targeted at parents and child care givers in order to reduce the incidence of poisoning in this sub-group.

There appeared to be significant ethnic differences in the proportion of poisoning cases with the 'others' and 'Indian' ethnicity being higher compared to the population census. However, the data could not be easily interpreted as Singapore has a migrant population of almost 1 million and they come mainly from the surrounding countries. The national population census data only refers to Singapore residents. Further studies need to be conducted to determine the ethnic contribution to poisoning episodes in the local context.

Since the last local study on type of poisoning agents more than 10 years ago $[12,13,15]$, the trend of poisoning agents has changed. Being a heavily industrialized developed nation, the occupational hazards posed by toxins are unique in their own way. Singapore's economy is strong on semiconductor, oil refining and chemical manufacturing. The small but substantial proportion of industrial accident cases in our study demonstrates this. With a combination of Western and traditional medicine practice, the variety of toxins that pose potential health hazards are numerous in the local context. In addition, despite being an urbanized country, there are many natural toxic hazards accounting for a variety of venomous land and marine creature envenoming. It is also noteworthy in this study that alcohol is noted to be an important agent involved in toxic exposures. This may be an underestimate of the actual extent of the problem as the cases tracked in this study only involved patients with acute alcohol intoxication as the primary diagnosis and failed to capture alcohol exposures in segments of populations seen for trauma but in which the alcohol exposure was not hard coded in the discharge diagnosis. The study seems to point to a significant economic and social burden of alcohol-related problems that the society faces. Studies to gain more specific insight into this problem from the public health perspective would be ideal.

Although poisoning including bites and stings made up only $1 \%$ of the total ED attendance, a sizable proportion of them were admitted (36.1\%). A significant proportion of these cases required intensive care management (4.7\%). This would add up to the cost of managing toxic exposures. Approximately a fourth of those who were admitted stayed for less than $24 \mathrm{~h}$. This may suggest that a short-term observation ward in the ED that could cater to this group of patients might help to reduce the overall admission rate while maintaining the necessary quality of care.

Although only $7.4 \%$ of poisoning cases reached the ED within $1 \mathrm{~h}$ of toxic exposure, there was a proportionally large number of patients $(11 \%)$ who received activated charcoal as a decontaminant possibly implying a more liberal attitude to its use despite standard guidelines which recommend it within $1 \mathrm{~h}$ of oral exposures. The study also alludes to the common antidotes that are commonly used in the local context and hence has important implications for minimum stocking levels of these antidotes. It is interesting to note that despite having venomous snakes in the country, and a small but not insignificant number of snakebites, none of the cases required the use of antivenom as there had been no significant envenoming. It is also important to note that there had been no reports of fatalities from snakebites during the study period.

Toxic exposure data could be used to guide training of health care providers and provide estimates of logistics required by hospitals in the management of poisoning. Specific protocols directed at the common poisons would help to standardize management as well as consistent use of antidotes and other decontamination procedures. A standard protocol for the management of acetaminophen poisoning as well as the use of $N$-acetyl-L-cysteine would be useful as this is the most common pharmaceutical poisoning agent and the antidote is the most commonly used antidote. A poison information centre would help to improve poison information dissemination and standardize management of poisoning. The management of poisoning has evolved with time [17], and the most up-to-date evidence-based measures should be used for optimal management of the poisoned patient.

In conclusion, this is the most extensive study on toxic exposure epidemiology in Singapore. The extrapolated toxic exposure rate of 1.7 per 1,000 population per year is comparable to that in other developed countries. Although the case fatality rate is low at 0.8 per 1,000 exposures, about a third of the cases required admission of which two thirds were admitted for more than $24 \mathrm{~h}$.

\section{Limitations}

This study is a retrospective review of poisoning data and only includes poisonings presenting to the ED of three public hospitals. Minor poisoning cases that present to the primary health care setting or were self-treated as well as fatality cases that did not make it to the hospital were not captured in this study. As the case identification involved a combination of voluntary reporting and ICD code data mining of hospital computerized databases, data capture is likely to be incomplete with an expected underestimation of actual case load.

Acknowledgements We would like to thank all the physicians, nurses and research coordinators who contributed to this study and made it possible.

Conflicts of interest None. 


\section{References}

1. Watson WA, Litovitz TL, Rodgers GC et al (2005) 2004 Annual report of the American Association of Poison Control Centers Toxic Exposure Surveillance System. Am J Emerg Med 23:589666

2. Fathelrahman AI, Ab Rahman AF, Mohd Zain ZM (2005) MS 04044: demographic features of drug and chemical poisoning in northern Malaysia. Clin Toxicol (Phila) 43:89-94

3. Akkose S, Bulut M, Armagan E, Cebicci H, Fedakar R (2005) Acute poisoning in adults in the years 1996-2001 treated in the Uludag University Hospital, Marmara Region, Turkey. Clin Toxicol (Phila) 43:105-109

4. Afshari R, Majdzadeh R, Balali-Mood M (2004) Pattern of acute poisonings in Mashhad, Iran 1993-2000. J Toxicol Clin Toxicol 42:965-975

5. Goksu S, Yildirim C, Kocoglu H, Tutak A, Oner U (2002) Characteristics of acute adult poisoning in Gaziantep, Turkey. J Toxicol Clin Toxicol 40:833-837

6. Hanssens Y, Deleu D, Taqi S (2001) Etiologic and demographic characteristics of poisoning: a prospective hospital-based study in Oman. J Toxicol Clin Toxicol 39:371-380

7. Liu Y, Wolf LR, Zhu W (1997) Epidemiology of adult poisoning at China Medical University. J Toxicol Clin Toxicol 35:175-180

8. Thomas SHL, Bevan L, Bhattacharyya S et al (1996) Presentation of poisoned patients to accident and emergency departments in the north of England. Hum Exp Toxicol 15:466-470

9. Chan YKT, Critchley JAJH, Chan TVM, Yu CM (1994) Drug overdosage and other poisoning in Hong Kong - the Prince of Wales Hospital (Shatin) experience. Hum Exp Toxicol 13:512-515

10. Ministry of Health, Health Facts Singapore. (http://www.moh.gov. $\mathrm{sg} / \mathrm{mohcorp} /$ statistics.aspx?id=5528)

11. Ng DW, Lau G (2003) Suicide trends in Singapore: two decades down the road. Med Sci Law 43:141-147

12. Tay SY, Tai DY, Seow E, Wang YT (1998) Patients admitted to an intensive care unit for poisoning. Ann Acad Med Singapore $27: 347-352$
13. Ho L, Heng JT, Lou J (1998) Accidental ingestions in childhood. Singapore Med J 39:5-8

14. Ponampalam R, Anantharaman V (2002) Determining the extent of adverse drug reactions and poisonings encountered by physicians in Singapore. SGH Proceedings 11:17-25

15. Choa TC, Lo DS, Bloodworth BC (1992) Common poisons in Singapore - past and present. Med Sci Law 32:139-147

16. Ministry of Health, Hospital Stats. (http://www.moh.gov.sg/ mohcorp/statistics.aspx?id=242)

17. Tan HH, Goh SH (2006) Toxicology today. Singapore Med J 47:1016-1017

Dr. Ponampalam has spent most of his working years at Singapore General Hospital (SGH) as an Emergency Physician since 1995. Soon after he pursued his sub-speciality interest in toxicology and was given the Health Manpower Development Programme (HMDP) Award from the Ministry of Health (MOH) for training in emergency toxicology in the USA in 1998. Upon his return he has invaluably contributed to the hazardous materials disaster preparedness programme both nationally and at the hospital level. $\mathrm{He}$ was instrumental in having developed programmes in hazardous materials life support (HMLS) courses which have been endorsed by the $\mathrm{MOH}$ as a national training programme for emergency responders dealing with chemical disasters. His interest in toxicology has spurred him on to set up the first national Drug and Poison Information Center (DPIC) in Singapore of which he was the director. He currently sits on $\mathrm{MOH}$ committees advising on toxicology matters. Academically he is senior clinical lecturer at the National University of Singapore (NUS) medical faculty, lecturer at Nanyang Polytechnic (NYP) teaching nurses in the advanced diploma in the nursing programme and is also visiting lecturer to the Singapore Civil Defense Force (SCDF) on Chemical, Biological, Radiological and Explosives (CBRE) medical management. 